\title{
Klasifikasi Daging Sapi Berdasarkan Ciri Warna Dengan Metode Otsu dan Euclidean Distance
}

\author{
Adi Rizky Pratama \\ Universitas Buana Perjuangan \\ Karawang \\ Karawang, Indonesia \\ adi.rizky@ubpkarawang.ac.id
}

\author{
Ayu Ratna Juwita \\ Universitas Buana Perjuangan \\ Karawang \\ Karawang, Indonesia \\ ayurj@ubpkarawang.ac.id
}

\author{
Tohirin Al Mudzakir \\ Universitas Buana Perjuangan \\ Karawang \\ Karawang, Indonesia \\ tohirin@ubpkarawang.ac.id
}

\begin{abstract}
Abstrak - Setiap daging sapi memiliki kualitas yang berbeda. Kualitas daging sapi dapat di bedakan dengan warna daging sapi sesuai dengan Badan Standardisasi Nasional yang di bedakan menjadi beberapa klasifikasi. Pengklasifikasian diberi label 1 sampai 9, dimana label 1 adalah klasifikasi kualitas daging terendah dan nilai 9 adalah klasifikasi kualitas daging tertinggi. Penelitian ini membahas cara mengklasifikasikan daging sapi berdasarkan ciri warna daging dengan menggunakan metode klasifikasi euclidean distance. Langkah pertama dengan preprocessing dilalukan untuk mengubah citra berwarna menjadi grayscale. Langkah berikutnya segmentasi citra yang akan memisahkan citra daging menjadi 2 yaitu daging dan lemak menggunakan metode otsu. Lalu ekstraksi warna untuk mendapatkan nilai warna. Langkah terakhir pengklasifikasian dengan metode euclidean distance. Dengan metode ini di dapatkan hasil akurasi $72 \%$ untuk klasifikasi daging, Dan rata-rata nilai precision adalah sebesar $65 \%$ dan rata- rata recall $77 \%$.
\end{abstract}

Kata kunci — Daging Sapi, Euclidean Distance, Klasifikasi Daging Sapi, Otsu.

Abstrack - Each beef has a different quality. The quality of beef can be distinguish with the color of the beef according to the national standardization body which is divided into several classifications. This study discusses how to classify beef based on the color characteristics of meat using Euclidean distance classification method. The first step is with the preprocessing channeled to turn the colored image into grayscale. The next step of image segmentation that will separate the meat image into 2 namely meat and fats using the Otsu method. Then extract the colors to get the color values. The final step of classifying by Euclidean distance. With this method, get a $72 \%$ accuracy result for the meat classification and the average precision value is $65 \%$ and the average of $77 \%$ for the meat recall.

Keywords — beef, classification of beef, Euclidean Distance, Otsu.

\section{Pendahuluan}

Atribut utama untuk menentukan kualitas daging sapi antara lain rasa, aroma, warna, perlemakan (marbling) dan tekstur. Warna daging sapi yang baik adalah berwarna merah cerah. Menurut Badan Standardisasi Nasional prosedur penilaian mutu fisik lemak dan daging sapi terbagi menjadi sembilan penilaian.

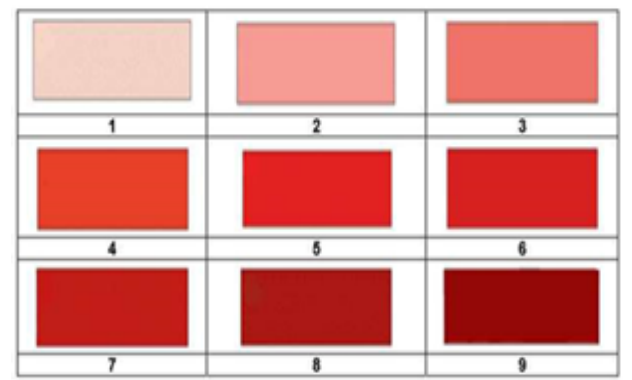

Gambar 1 : Standart Warna Karkas Sapi [1]

Model naskah ini, dibuat dalam MS Word 2007 dan disimpan sebagai "Word 97-2003 Document" untuk PC, menyediakan penulis dengan sebagian besar spesifikasi format yang berbeda dan diperlukan untuk menyiapkan versi elektronik dari makalah mereka. Semua komponen naskah secara baku telah ditentukan karena kemudahan penggunaan saat memformat naskah dan kelayakan publikasi naskah elektronik. Margin, lebar kolom, penspasian garis, dan tipe gaya sudah ada di dalamnya; contoh gaya tipe disediakan di seluruh dokumen ini dan diidentifikasi

Penelitian klasifikasi daging sapi yang telah di lakukan oleh beberapa peneliti sebelumnya antaralain [5] melakukan penelitian untuk klasifikasi dengan hasil akurasi mencapai 90\% untuk daging segar [6], namun penelitian ini memiliki tingkat akurasi sebesar $80 \%$ pada daging segar.Dalam penelitian [7] tidak di sebutkan presentase keberhasilan namun dinyatakan dapat mengklasifikasi daging sapi. Namun di sini yang di klasifikasi 3 ciri yaitu

warna daging, warna lemak dan marbling. Karna ini peneliti lebih banyak menggunakan metode image prosesing dan klasifikasi yang di gunakan pada penelitian ini. namun [8] menggunakan metode otsu dalam segmentasi yang diharapkan lebih baik daripada tresholding. Memisahkan proses perhitungan warna daging dan warna lemak. Dan hanya fokus pada ciri warna yang terdapat

pada daging dan lemak sapi. Perbandingan Euclidean Distance Dengan Canberra Distance Pada Face Recognition [9] tingkat kemiripan (similarity) paling tinggi yaitu pada gambar menghadap kanan dengan radius 1 meter dengan metode Euclidean Distance. Sedangkan percobaan yang dilakukan menggunakan metode Canberra Distance, tingkat kemiripan (similarity) paling tinggi pada gambar menghadap depan dengan radius jarak 1 meter. Perbedaan penelitian sebelumnya dengan penelitian yang akan dilakukan pada penelitian ini, diantaranya adalah : 1. Penelitian menggunakan metode otsu untuk segmentasi. 2. Menggunakan 3 warna HSV (Hue, Saturation, Value) dengan mengambil nilai rata-rata dari setiap warna HSV. 3. Mengklasifikasikan kedalam 9 klasifikasi untuk daging. 4. Klasifikasi menggunakan metode euclidean distance.

Untuk melakukan klasifikasi tingkat kualitas daging sapi dapat dilakukan dengan menggunakan teknologi dengan memanfaatkan pengolahan citra. Pengolahan citra adalah cabang ilmu informatika untuk melakukan proses pengolahan gambar digital atau citra 
berdasarkan titik-titik piksel dengan mengambil informasi pada citra untuk tujuan tertentu. Lalu klasifikasi dari gambar yang telah di proses menggunakan metode euclidean distance. Pada penelitian ini menggunakan daging sapi lokal.

\section{TINJAUAN PUSTAKA}

\section{A. $H S V$ (Hue, Saturation, Value)}

Model HSV mendefinisikan warna terhadap 3 komponen :Hue(H), Saturation(S) dan Value(V). Komponen Hue mewakili warna sebenarnya seperti Merah, Kuning, Hijau, Cyan, Biru dan lain-lain. Komponen Saturation(S) mewakli besaran kemurnian warna. Memberikan ukuran berapa banyak warna yang sebenarnya ditambahkan dengan putih. Nilai satu Saturation dibuat presentase jika nilai saturation 0 maka warna keabu-abuan. Jika 100 maka warna murni. Value (V) adalah analog kecerahan. Suatu warna dengan warna value 100 akan tampak cerah dan jika nilai saturation 0 maka warna akan tampak lebih gelap[2] Mode HSL merupakan mode yang ditemukan oleh.

\section{B. Citra}

Citra dapat diartikan sebagai gambaran yang tampak dari suatu objek yang sedang diamati sebagai hasil liputan atau rekaman suatu alat pemantau. Contoh memotret bunga di taman. Menurut Hornby citra adalah gambaran yang terekam oleh kamera atau alat sensorlain, adapun menurut simonet citra adalah gamabran rekaman suatu objek biasanya berupa berupa gambaran pada citra yang diperoleh melalui cara optic, elektro-optik, optic-mekasnik atau elektro mekanik[3]. Pengolahan citra digital merujuk pada proses gambar 2 dimensi yang menggunakan komputer. Citra digital merupakan array yang berisi nilai-nilai real maupun komplek yang direpresentasikan dengan deretan bit tertentu. (Putra, 2010) Secara matematis fungsi intensitas cahaya pada bidang 2D disimbolkan dengan $\mathrm{f}(\mathrm{x}, \mathrm{y}) .(\mathrm{x}, \mathrm{y})$ : koordinat kartesian.f(x,y) : intensitas cahaya (brightness) pada titik $(\mathrm{x}, \mathrm{y})$.

\section{Metode Otsu}

Metode otsu menghitung nilai ambang secara otomatis berdasarkan citra masukan. Pendekatan yang digunakan oleh metode otsu adalah dengan melakukan analisis diskriminan yaitu menentukan suatu variable yang dapat membedakan antara dua atau lebih kelompok yang muncul secara alami. Analisis diskrimanan akan memaksimumkan variable tersebut agar dapat memisahkan objek dengan latar belakang[4].

Prinsip metode otsu dijelaskan sebagai berikut ini. Pertama-tama , probabilitas nilai intensitas i dalam histogram dihitung melalui

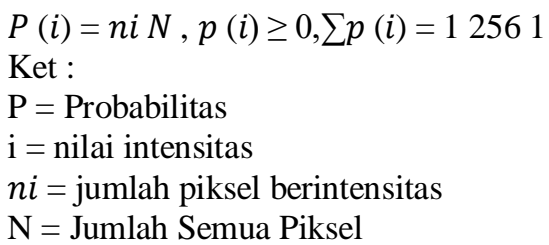

Dengan $n i$ menyatakan jumlah piksel berintensitas i dan $\mathrm{N}$ menyatakn jumlah semua piksel dalam citra. Jika histogram dibagi menjadi dua kelas (objek dan latarbelakang), pembobotan pada kedua kelas dinyatakan sebagai berikut :

$$
\begin{aligned}
& w 1(t)=\sum p(i) \\
& w 2(t)=\sum p(i)=1-w 1(t) \\
& L i=t+1 \\
& \text { Keterangan : } \\
& \mathrm{W}=\text { nilai bobot } \\
& \mathrm{L}=\text { jumlah aras keabuan }
\end{aligned}
$$

\section{Euclidean Distance}

Algoritma ini adalah metode yang digunakan untuk klasifikasi terhadap objek berdasarkan data contoh berdasarkan jarak yang paling dekat dengan objek tersebut.

Pada saat training algoritma hanya menyimpan vector-vektor fitur dan klasifikasi data training sample. Pada step klasifikasi fiturfitur yang sama dihitung untuk testing data pada step ini klasifikasi belum diketahui. Lalu dihitung jarak dari data traning sample terhadap vector uji. euclidean distance ialah metode yang sering di gunakan untuk menghitung ksamaan . rumus euclidean distance adalah akar dari kuadrat perbedaan 2 vektor. Keterdekatan ditentukan dalam hal sejumlah jarak matrik seperti jarak euclidean distance. Jika diberi 2 buah titik $\mathrm{P}$ dan $\mathrm{Q}$ maka jarak euclidean antara dua poin :

$$
\operatorname{Dist}(\mathrm{P}, \mathrm{Q})=\sqrt{\sum_{i=1}^{n}\left(p_{i}-q_{i}\right)^{2}}
$$

Dimana $\mathrm{P}$ dan $\mathrm{Q}$ adalah titik pada ruang vector $\mathrm{n}$ dimensi sedangkan pi dan qi adalah besaran skalar untuk dimensi ke I dalam ruang vector $\mathrm{n}$ dimensi.

\section{Metodologi Penelitian}

Metode untuk menyelesaikan masalah degan memanfaatkan pengolahan citra dengan klasifikasi warna daging sapi. Adapun pengolahan citra dengan metode sebagai berikut : 


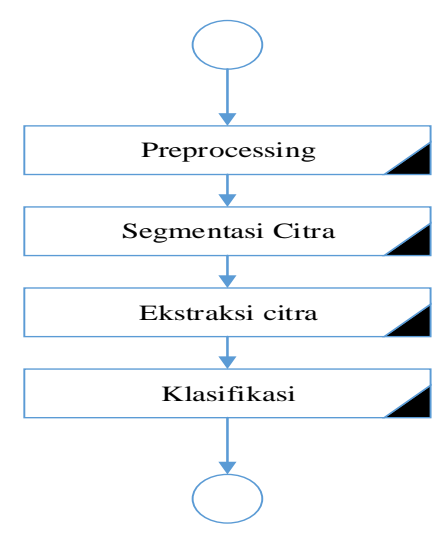

Gambar 2 : Metode Penelitian

\section{Preposesing}

Model klasifikasi daging sapi dan model data latih untuk klasifikasi daging sapi sederhana ditunjukan pada gambar berikut :

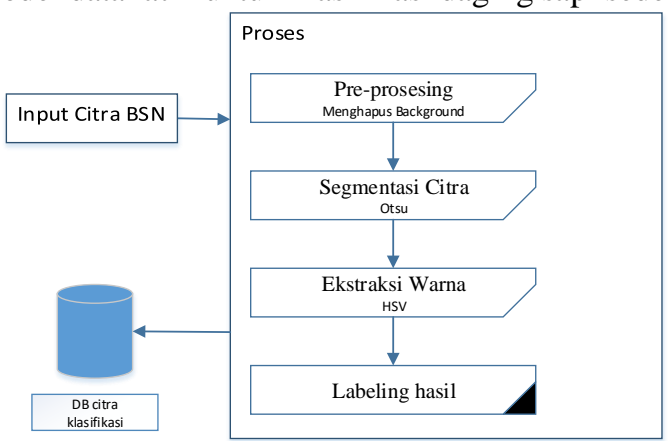

Gambar 3: Konsep data latih daging sapi

Datalatihyang digunakan adalah 9 klasifikasi warna dari BSN. Yang di ambil nilai RGBnya.

Konsep data latih daging sapi terdiri dari 3 proses, yaitu

Input : Proses pengambilan citra Uji

Proses : hasil dari preprosesing,segmentasi dan ekstraksi citra akan di klasifikasi kan dengan data set yang ada dalam database.

Output : Hasil Klasifikasi daging Sapi

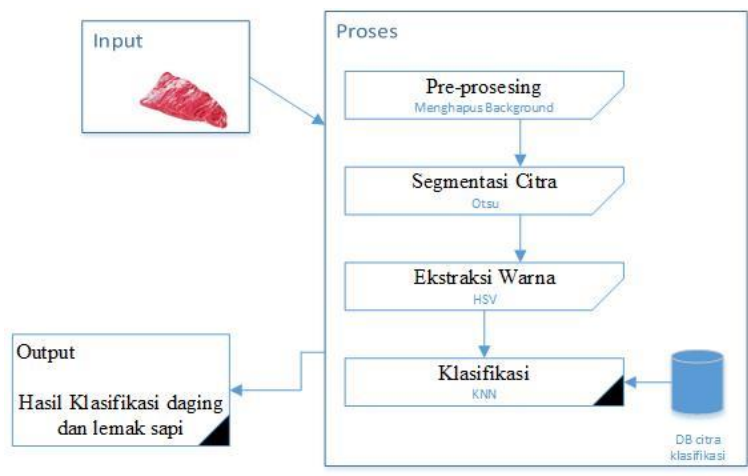

Gambar 4: Konsep klasifikasi daging sapi

Konsep klasifikasi daging sapi terdiri dari 3 proses, yaitu

Input : Proses pengambilan citra Uji

Proses : hasil dari preprosesing,segmentasi dan ekstraksi citra akan di klasifikasi kan dengan data set yang ada dalam database. Output : Hasil Klasifikasi daging Sapi

\section{A. Akusisi citra}

Data pengambilan citra yang dilakukan menggunakan blackbox, yaitu alat yang berguna agar mempermudah dan mengambil citra dengan kualitas yang baik, selain itu dengan menggunakan alat blackbox akan menambah tingkat keakuratan hasil dari input citra yang diperoleh, hasil citra yang diperoleh menggunakan alat blackbox memiliki background berwarna hijau dan pencahayaan normal untuk mempermudah dan memperjelas pada saat Pre-Processing, berikut adalah hasil pengambilan citra dengan menggunakan alat blackbox. 


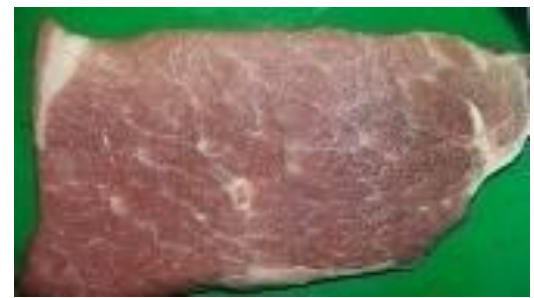

Gambar 5 : Gambar Daging

\section{B. Preprocessing.}

Pada tahap ini dilakukan penghilangan background agar gambar hanya mesisakan citra daging dan lemak. metode $(x, y)\left\{\begin{array}{l}1 \text { iff }(\mathrm{x}, \mathrm{y}) \geq \mathrm{T} \\ 0 \text { iff }(\mathrm{x}, \mathrm{y})<\mathrm{T}\end{array}\right.$ $\mathrm{g}(\mathrm{x}, \mathrm{y})$ : nilai pixel hasil thresholdpada baris $\mathrm{x}$ dan kolom $\mathrm{y}$

$\mathrm{f}(\mathrm{x}, \mathrm{y})$ : nilai pixel dari citra input asal pada baris $\mathrm{x}$ dan kolom $\mathrm{y}$

$\mathrm{T}$ : nilai threshold sebagai batas nilai keabuan untuk mengkonversi nilai pixel $f(x, y)$ menjadi nilai pixel $g(x, y)$.

untuk menentukan objek daging dan background. Dengan memecah nilai R,G,B. lalu menyeleksi jika warna merah dan hijau lebih besar dari 50, untuk menghilangkan background dan bayangan pada citra.

Tahap selanjutnya merubah citra warna menjadi grayscale. Citra grayscale disusun oleh angka antara 0 sampai 255 . Untuk merubah warna RGB kedalam grayscale di matlab menggunakan rumus berikut :

Grayscale $=0.299 *$ Red $+0.587 *$ Green $+0.114 *$ Blue

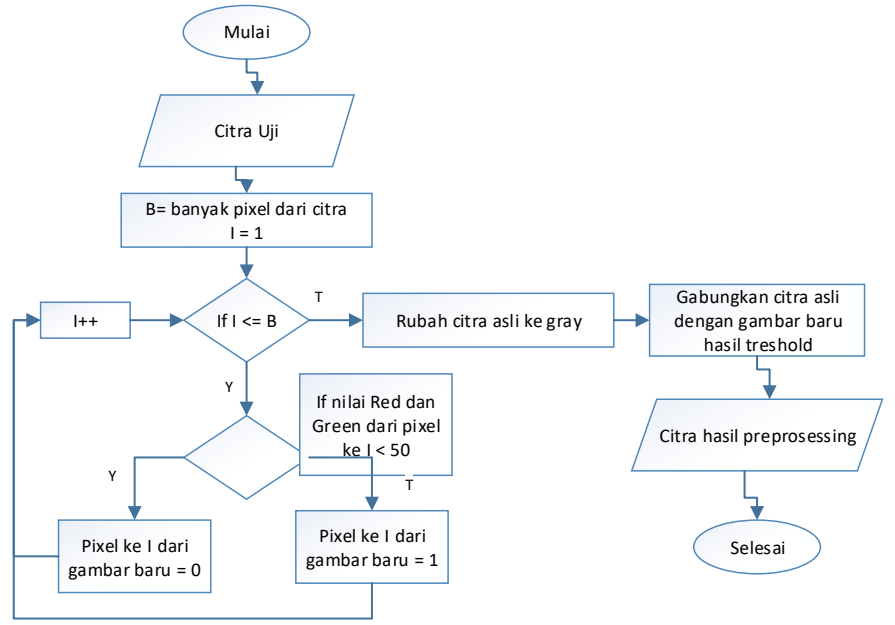

Gambar 6: Alur Proses Preprosessing

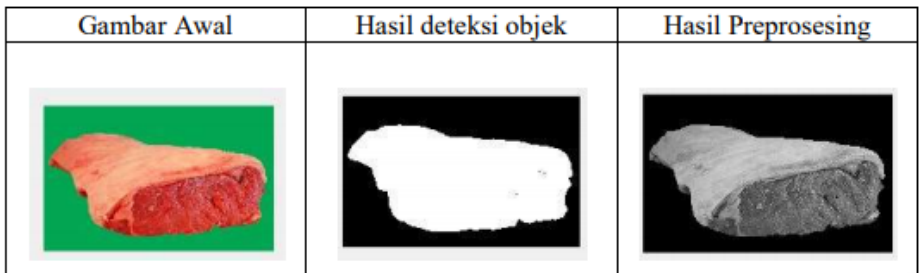

Gambar 7: (a) Gambar Hasil Tahap Sebelumnya, (b) Gambar Hasil Deteksi Objek, (c) Gambar Hasil Processing

Gambar awal adalah citra asli dari daging, lalu di seleksi background sehingga menghasilkan gambar gasil deteksi objek yang menggunakan metode threshold. Setelah di seleksi di gabungkan dengan gambar awal dan di buat grayscale untuk segmentasi citra seperti gambar hasil preprosessing.

\section{Segmentasi Citra}

Hasil dari preprocessing akan di proses dengan di potong menjadi 3 bagian. Backgroun, daging dan lemak.

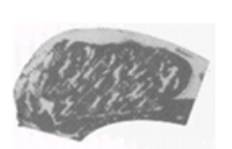

(a)

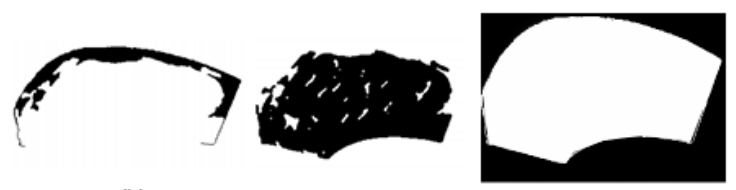

(b)

Gambar 8 : (a) Gambar Hasil Tahap Sebelumnya, (b) Gambar Lemak, (c) Gambar Daging, (d) Gambar Background

Otsu yang berbasis pada citra tingkat keabu-abuan. metode ini tanpa mengurangi kecerahan gambar dan karakteristrik kontras, metode ini membaca ambang batas lebih akurat di bandingkan histogram. 


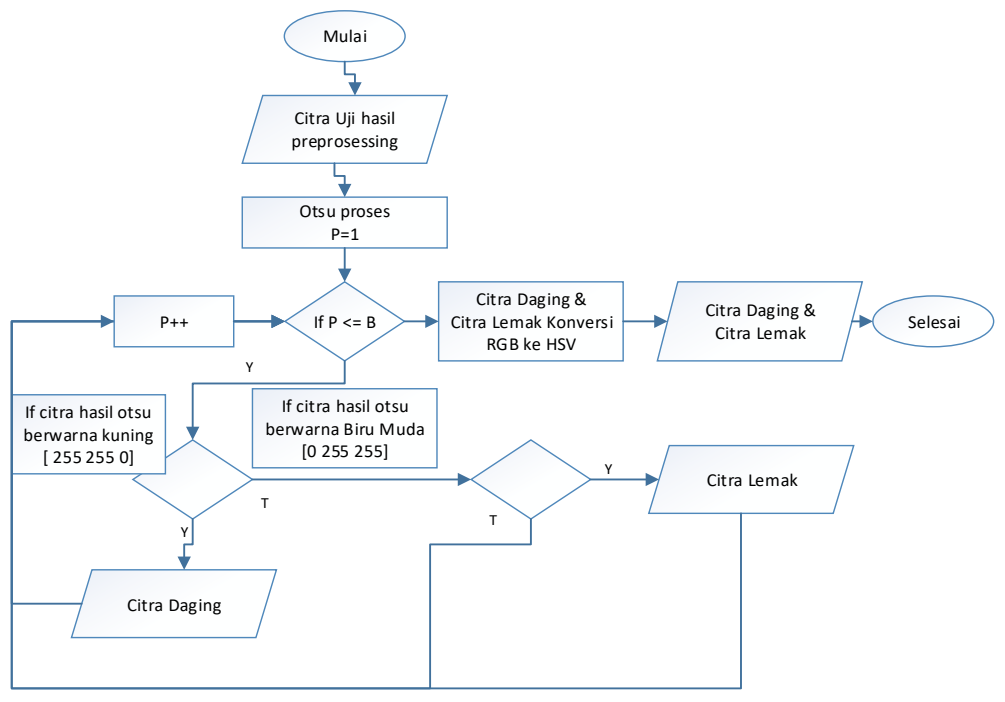

Gambar 9: Alur Proses Segmentasi

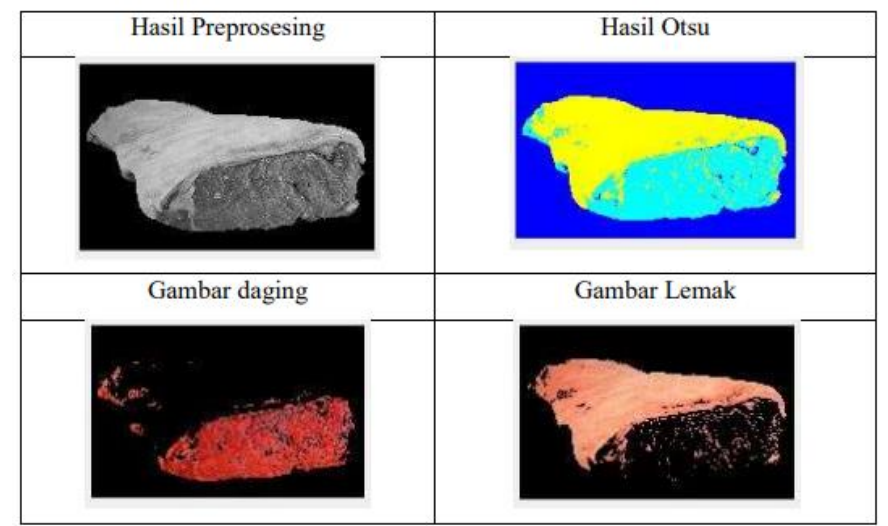

Gambar 10 : (a) Gambar Hasil Tahap Sebelumnya, (b) Proses Otsu, (c) Gambar Daging, (d) Gambar Lemak

Gambar menunjukan hasil dari proses otsu. Memisahkan background daging dan lemak.

\section{Ekstraksi Fitur}

Perhitungan warna yang pertama memecah nilai RGB menjadi 3 lapisan (Red, Green dan Blue) yang akan di konversi ke HSV. Lalu menjumlahkan nilai warna pada masing-masing jenis warna yang dilakukan secara baris dan kolom.

$$
\text { total }_{\text {warna }}=\sum_{i=1}^{m} \sum_{j=1}^{n} \text { jenis }_{\text {warna }_{(i j)}}
$$

Menghitung nilai rata-rata warna dengan menjumlahkan semua nilai warna pada jenis warna tertentu lalu dibagi dengan total banyaknya warna bukan hitam pada citra.

$$
\text { Mean }=\frac{\text { total_warna }}{N}
$$

Pengambilan nilai warna didapat dari nilai rata-rata warna lemak dan daging sapi berdasarkan ruang warna HSV dan RGB.

\section{E. Klasifikasi}

Tahap terakhir adalah pengklasifikasian yang menggunakan metode euclidean distance. Keterdekatan ditentukan dalam hal sejumlah jarak matrik seperti jarak euclidean distance. Jika diberi 2 buah titik P dan Q maka jarak Euclidean antara dua poin :

$$
\begin{gathered}
\mathrm{P}=\left(\mathrm{P}_{1}, \mathrm{P}_{2}, \ldots, \mathrm{P}_{\mathrm{n}}\right) \text { dan } \mathrm{Q}=\left(\mathrm{Q}_{1}, \mathrm{Q}_{2}, \ldots, \mathrm{Q}_{\mathrm{n}}\right) \text { adalah : } \\
\operatorname{Dist}(\mathrm{P}, \mathrm{Q})=\sqrt{\sum_{i=1}^{n}\left(p_{i}-q_{i}\right)^{2}}
\end{gathered}
$$

Dimana $\mathrm{P}$ dan $\mathrm{Q}$ adalah titik pada ruang vector $\mathrm{n}$ dimensi sedangkan pi dan qi adalah besaran skalar untuk dimensi ke I dalam ruang vector $\mathrm{n}$ dimensi. 


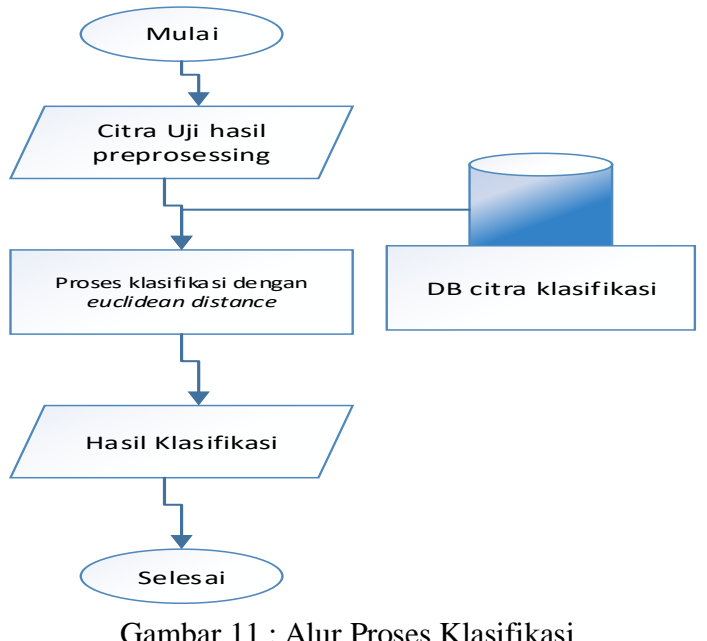

\section{F. Pengujian System}

Proses evaluasi yang dilakukan adalah dengan 50 citra uji yang telah dipilih sebelumnya. Parameternya adalah tingkat keakuratan citra yang telah diproses dan menghasilkan output yang benar sesuai klasifikasi BSN. Hasil evaluasi akan disajikan dalam bentuk tabel dengan membandingkan nilai yang di prediksi dengan nilai yang sebenarnya.Dengan bentuk confusion matrix multiclass.Adalah sebuah matriks yang memberikan gambaran tentang tingkat akurasi danpresisi (Faisal, 2016). Pengujian dilakukan pada beberapa jenis citra daging dan dataset kembali yang dilakukan sebanyak 50 citra.

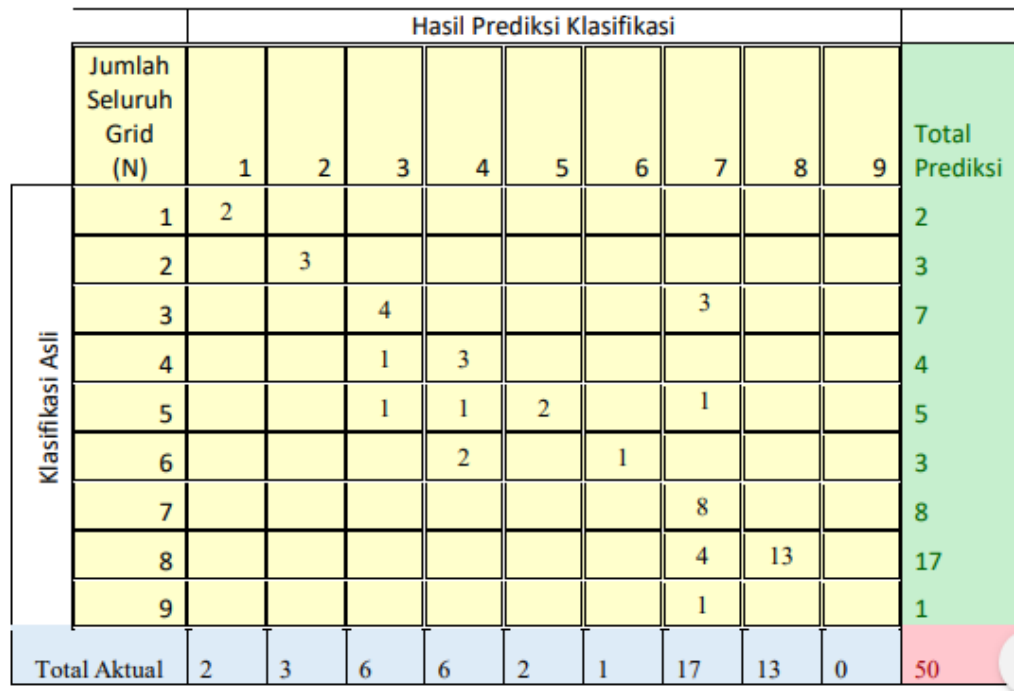

hasil nilai precision dan recall dari hasil percobaan daging

\begin{tabular}{|c|c|c|}
\hline Klasifikasi & Hasil Precision $\frac{T P(1)}{n P(1)}$ & Hasil Recall $\frac{T P(1)}{n A(1)}$ \\
\hline 1 & 1 & 1 \\
\hline 2 & 1 & 0.67 \\
\hline 3 & 0.57 & 0.5 \\
\hline 4 & 0.75 & 1 \\
\hline 5 & 0.4 & 1 \\
\hline 6 & 0.33 & 1 \\
\hline 7 & 1 & 0.77 \\
\hline 8 & 0.77 & 0 \\
\hline 9 & 0 & \\
\hline
\end{tabular}

Accuracy $=T P(1)+T P(2)+T P(3)+T P(4)+\cdots+T P(9) / N$

$=2+3+4+3+2+1+8+12 / 50$

$=3650=0.72$

menunjukan 50 kali percobaan klasifikasi daging pada citra uji yang menunjukan hasil akurasi sebesar $72 \%$.

Hasil precision dan recall dari Daging :

\begin{tabular}{|c|c|c|c|c|}
\hline Klasifikasi & Hasil Precision & Presentase & Hasil Recall & Presentase \\
\hline 1 & 1 & $100 \%$ & 1 & $100 \%$ \\
\hline
\end{tabular}




\begin{tabular}{|c|c|c|c|c|}
\hline Klasifikasi & Hasil Precision & Presentase & Hasil Recall & Presentase \\
\hline 2 & 1 & $100 \%$ & 1 & $100 \%$ \\
\hline 3 & 0.57 & $57 \%$ & 0.67 & $67 \%$ \\
\hline 4 & 0.75 & $75 \%$ & 0.5 & $50 \%$ \\
\hline 5 & 0.4 & $40 \%$ & 1 & $100 \%$ \\
\hline 6 & 0.33 & $33 \%$ & 1 & $100 \%$ \\
\hline 7 & 1 & $100 \%$ & 1 & $100 \%$ \\
\hline 8 & 0.77 & $77 \%$ & 0.77 & $77 \%$ \\
\hline 9 & 0 & $0 \%$ & 0 & $0 \%$ \\
\hline \multicolumn{2}{|r|}{ Rata- rata presentase } & $65 \%$ & & $77 \%$ \\
\hline
\end{tabular}

IV. HASIL DAN PEMBAHASAN

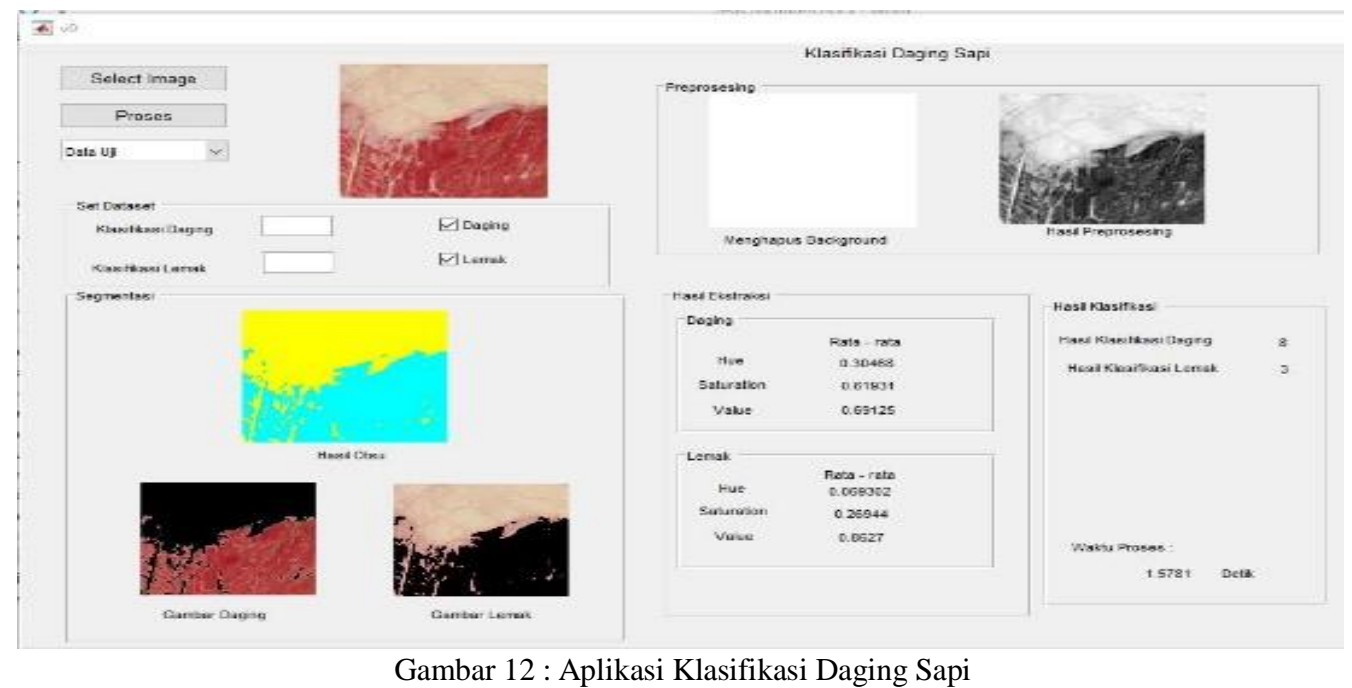

Dalam penerapan metode klasifikasi daging sapi ini dapat mengklasifikasikan dengan akurasi daging mencapai $72 \%$. Dan ratarata nilai precision adalah sebesar $65 \%$ dan rata- rata recall $77 \%$ untuk daging.

\section{KeSIMPUlan}

Metode ini dapat mengklasifikasi daging dan lemak sapi namun hasilnya masih belum sesuai dengan yang diharapkan.

Berdasarkan hasil penelitian maka saran yang dapat diberikan sebagai bahan acuan untuk penelitian selanjutnya adalah :

1. Penelitian dapat dilanjutkan dengan menggunakan metode lain yang berbeda untuk mengukur akurasi sehingga didapatkan hasil terbaik untuk klasifikasi daging sapi.

2. Perlunya mempercepat waktu proses untuk gambar lcitra yang berresolusi besar (lebih dari $1000 \times 1000$ ) terutama dalam proses otsu.

3. Penghapusan noise dari cahaya camera yang memantul pada citra daging.

\section{DAFTAR PUSTAKA}

[1] BSN, "Standar Nasional Indonesia 3932:2008 Mutu karkas dan daging sapi,” Standar Nas. Indones., pp. 1-14, 2008.

[2] V. Chernov, J. Alander, and V. Bochko, "Integer-based accurate conversion between RGB and HSV color spaces q," Comput. Electr. Eng., vol. 46, pp. 328-337, 2015.

[3] B. Utoyo, Geografi: Membuka Cakrawala Dunia. Bandung: PT Grafindo Media Pratama., 2006.

[4] D. Putra, Pengolahan Citra Digital. Yogyakarta: ANDI, 2010.

[5] Yuristiawan, D., Z. Rahmanti, F., \& Santoso, H. A. "APLIKASI PENDETEKSI TINGKAT KESEGARAN DAGING SAPI LOKAL MENGGUNAKAN EKSTRAKSI FITUR WARNA DENGAN PENDEKATAN STATISTIKA”. Riptek, 9- 16, 2015.

[6] Kiswanto , \& Sujono, "Identifikasi Citra Untuk Mengidentifikasi Jenis Daging Sapi Segar Menggunakan Wavelet". Teknologi Informatika dan Komputer Atma Luhur, 23-30, 2014.

[7] Adi, K., Pujiyanto, S., Dwi Nurhayati, O., \& Pamungkas, A. "Beef Quality Identification using Color Analysis and K-Nearest Neighbor Classification". International Conference on Instrumentation, Communications, Information Technology, and Biomedical Engineering , 180-184. 2015.

[8] Chang, R., Wei , Y., Ma, L., Wang, Y., Liu , H., \& Song1 , M. (n.d.) “ The Judgment of Beef Marble Texture Based on the MATLAB Image Processing Technology

[9] Wurdianarto, S. R., Novianto, S., \& Rosyidah, U. "PERBANDINGAN EUCLIDEAN DISTANCE DENGAN 